\title{
O Jogo nas aulas de Educação Física: significados atribuídos pelas crianças
}

\begin{abstract}
Resumo: Trata-se de uma reflexão teórica oriunda de uma experiência pedagógica a partir do trabalho com o conteúdo jogo nas aulas de Educação Física nas séries iniciais do Ensino Fundamental. Desse modo, nesse estudo temos como objetivo: analisar a forma como alunos do município de Ponta de Pedras/PA das séries iniciais do Ensino Fundamental produzem significados a respeito do conteúdo jogo, nas aulas de Educação Física. Referente aos procedimentos metodológicos, o estudo se encontra no campo da pesquisa-ação, utilizando-se da observação e de registros na forma de imagens, vídeos e materiais didáticos para a coleta de dados. Para análise, faz uso de um quadro bibliográfico alusivo à Filosofia e a Antropologia do jogo. Concluímos que o jogo apresenta inúmeros significados para as crianças em questão, expressos nos termos: brincadeira, alegria, diversão, professor, criança, corda, pessoas, poucas regras e podemos mudar regras. Tais termos, conforme se constatou na literatura especializada, apresentam-se como características fundamentais do fenômeno jogo.
\end{abstract}

Palavras-chave: Educação Física escolar. Jogo. Produção de significados.

\section{Introdução}

Historicamente o jogo tem sido tema de debates e de proposições em várias áreas do conhecimento. Tem sido comum também a associação do jogo e da ludicidade com as instituições educativas, sendo o jogo um recurso pedagógico em várias disciplinas e níveis de ensino, como, por exemplo, na disciplina de Arte, na Educação Infantil e nas séries iniciais do Ensino Fundamental.

O trabalho em questão é fruto de uma experiência pedagógica realizada no município de Ponta de Pedras/PA, localizado na região da Ilha do Marajó, que fica a cerca de 44 quilômetros de distância da capital do estado (Belém). O acesso à cidade somente pode ser realizado por meio de avião ou barco, o que aponta para a especificidade da cidade, que é cercada pelo rio e pela floresta amazônica. Em relação ao número de habitantes, a cidade possui aproximadamente 29.000 moradores $^{1}$.

A experiência pedagógica ligada a esta pesquisa aconteceu em uma escola, anexo da maior instituição estadual de ensino do município, com alunos do $3^{\mathrm{a}}$ ano do Ensino Fundamental, que estudam no turno da tarde. A referida escola, denominada E.E.E.M.F Joelson dos Santos Rodrigues, atualmente possui 31 alunos distribuídos em três turmas de Ensino Fundamental, e 40 alunos de Ensino Médio, que em geral, são moradores da própria comunidade. A
Renan Santos Furtado Universidade Federal do Pará Escola de Aplicação renan.furtado@yahoo.com.br Gabriel Pereira Paes Neto Universidade Federal do Pará e Secretaria de Estado de Educação do Pará gabrieledfisica@hotmail.com (1) Informações obtidas no site da prefeitura municipal de Ponta de Pedras. Disponível em: https:// www.pontadepedras.pa.gov.br/ omunicipio.php. Acesso em: 2 jun. 2019. 
(2) Práticas corporais serão aqui consideradas como fenômenos humanos, que possuem intensa relação com os elementos socioculturais de um determinado contexto. Por isso, as práticas corporais incorporam e superam ao mesmo tempo as elaborações daquilo que se considera movimento enquanto deslocamento corporal ou de membros do corpo. Em geral tais práticas são manifestadas em jogos, danças, ginásticas, esportes, lutas, circo, práticas de aventura e outras formas de experiências com o corpo (FURTADO; BORGES, 2019). escola se localiza em um território afastado do centro da cidade, na região das praias, ou como os alunos costumam falar "no interior de Ponta de Pedras".

A opção pelo termo experiência pedagógica parte de uma ideia de que a Educação é um espaço de construção de experiências que devem transcender o tempo e espaço da escola. No sentido de Benjamin (1985), a experiência em sua dimensão positiva é sempre um processo de transmissão de uma determinada informação/cultura de geração para geração por via da narração. Segundo Lessa (2016), essa noção exposta pelo pensador alemão é similar à ideia de Educação como momento de socialização da cultura.

Assim, diferentemente da pobreza da experiência formativa que de acordo com Benjamin (1985) caracteriza a infância na era da modernidade dominada pela racionalidade técnica, buscamos discutir e concretizar vias e possibilidades para uma imbricação formativa entre o ato pedagógico e a apropriação/recriação da cultura. Em uma reorganização do conceito para o momento de ensino-aprendizagem, concebemos a experiência como algo que pode "afetar" o sujeito, e com isso fazer com que o sujeito modifique sua forma de agir no mundo.

A partir de uma experiência pedagógica com o conteúdo jogo, a primeira inquietação que a prática docente nos apresentou se refere à maneira como os alunos compreendiam e davam significados para os conhecimentos estudados. Desse modo, apresentamos a seguinte questão de pesquisa: de qual forma alunos do município de Ponta de Pedras/PA das séries iniciais do Ensino Fundamental produzem significados a respeito do conteúdo jogo nas aulas de Educação Física? Assim, temos como objetivo: analisar a forma como alunos do município de Ponta de Pedras/PA das séries iniciais do Ensino Fundamental produzem significados a respeito do conteúdo jogo nas aulas de Educação Física.

A seguir apresentaremos os elementos do processo metodológico desenvolvido. Em seguida, adentraremos nas discussões sobre a caracterização do jogo como fenômeno humano e como prática corporal $^{1}$, e a relação entre jogo e cultura. Dando prosseguimento, centraremos esforços nas discussões dos resultados, momento em que também será realizado o diálogo com os referencias teóricos que norteiam nossa reflexão a respeito do fenômeno jogo. Por último, exporemos as sínteses a respeito do significado do jogo para o grupo estudantil em questão e nossas considerações finais. 


\section{Metodologia}

A respeito dos procedimentos metodológicos, em relação à modalidade da pesquisa, o estudo em questão se encontra no campo da pesquisa-ação. Pois, de acordo com Severino (2016), na pesquisa-ação ao mesmo tempo em que se estuda um determinado fenômeno, busca-se também interferir em sua dinâmica de forma intencional. Como técnica de coleta de dados, fizemos uso da observação do próprio fenômeno durante o processo de ensino-aprendizagem, do registro no caderno de anotações e da produção de material didático, que se tornou também fonte de dados.

Desse modo, foi justamente por via do uso de uma atividade de registro, que denominamos de caderno de jogos, que conseguimos compreender o significado do jogo para as crianças do Ensino Fundamental. No caderno, as crianças desenharam momentos e acontecimentos marcantes que vivenciaram com o conteúdo jogo durante as aulas, assim como, escreveram sobre as características do jogo, nos quais podem brincar na sua cidade, e citaram exemplos de jogos populares.

A experiência ocorreu entre o mês de dezembro de 2017 e mês de janeiro 2018, compondo o último bimestre letivo do planejamento da rede estadual de ensino. Realizamos cinco aulas de $1 \mathrm{~h}$ e 30 min com uma turma $3^{\circ}$ ano do Ensino Fundamental, sendo um encontro realizado a cada semana. Nessas aulas, o conteúdo jogo foi o tema principal, mais especificamente os jogos populares ou tradicionais na perspectiva de Kishimoto (2011), e os jogos de dramatização tratados por Bregolato (2007).

Outro aspecto importante para contextualizar a prática pedagógica em questão e os futuros dados oriundos da experiência, refere-se ao histórico dos estudantes e da escola com o componente curricular Educação Física. Como a escola fica afastada do centro comercial da cidade, as dificuldades com estrutura física, corpo docente, recursos financeiros, merenda escolar etc., são bem maiores do que as enfrentadas nas escolas do centro da cidade. Em decorrência desses aspectos, as crianças estavam sem professor de Educação Física praticamente durante todo o ano letivo de 2017, fato esse que comprova a situação de um contato assistemático e casual das crianças com o campo de conhecimento das práticas corporais. Com esse cenário, temos implicações não somente na compreensão distorcida das crianças sobre a função da Educação 
Física na escola, mas também, nas práticas cotidianas de ensino-aprendizagem.

Por último, é importante frisar que fizemos uso de uma metodologia de pesquisa na qual a própria aula se configurou como um momento de coleta e de análise de dados. Nessa perspectiva, os elementos teóricos sobre o jogo foram usados para explicar os discursos e os registros realizados pelas crianças, e não como categorias a priori. Sendo assim, a discussão conceitual que faremos a seguir pode ser considerada como uma forma de explicação e de entendimento do fenômeno que corrobora com a experiência pedagógica em questão.

\section{O jogo como fenômeno humano e como prática corporal}

Como se tem discutido historicamente, o jogo é um fenômeno com elevado grau de aspectos que primam pelo protagonismo do sujeito em suas estruturas, o que em termos filosóficos podemos chamar de uma atividade subjetiva, ou seja, aquilo que perpassa pelo maior domínio do sujeito. Por esse ângulo, é possível dizer que o jogo é uma atividade na qual o predomínio das ações e das suas formas de acontecer pertence ao sujeito, ou como denominamos anteriormente, é uma atividade subjetiva. Todavia, será se é pertinente a afirmação de que o jogo é exclusivamente uma prática corporal? Todo jogo é uma prática corporal? Podem existir jogos que não sejam práticas corporais?

A primeira questão conceitual sobre o jogo e importante para este trabalho é que tal atividade é por natureza um fenômeno interdisciplinar, assim, filósofos, sociólogos, historiadores, educadores e psicólogos têm se interessado em compreender o ato de jogar (KISHIMOTO, 2011). Nesse sentido, ainda que o jogo seja tradicionalmente associado à área da Educação Física, não é prudente dizer que o jogo é única e exclusivamente uma prática corporal. Vejamos como alguns teóricos tratam o jogo e o relacionam com o "devir" histórico e "evolutivo" humano, portanto, com a cultura.

Fundamentado em uma perspectiva materialista-história, Benjamin (1985) afirma que o jogo está presente desde o surgimento da humanidade no processo de desenvolvimento das primeiras formas de linguagem. Nesse sentido, o autor aponta que os jogos são carregados das representações da própria vida, de potencial 
imaginativo e construtivo de significados, dimensão essa que o autor denominou de faculdade mimética - potencial de imitabilidade dos homens. Portanto, podemos identificar a presença do jogo desde quando os seres humanos passaram a imaginar, criar, gesticular e se comunicar devido às necessidades da vida.

Não distante da linha de Benjamin, Kant (2010) ao discutir as três grandes faculdades humanas, que são, a imaginação, o entendimento e a sensibilidade, coloca à disposição humana para o jogo dentro da dimensão da imaginação, justamente essa ser a faculdade mais livre e criativa da ação humana.

Em uma linha de continuidade ao debate de Kant, para o filósofo alemão Schiller (2002), o jogo é uma atividade que completa o sentido da existência humana. Dessa maneira, não somente de racionalidade vive o homem, mas também de sensibilidade - que se atrela a imaginação -, sendo essa a dimensão primordial do jogo. Portanto, o jogo é algo que completa o sentido da existência do homem, sendo assim, é o momento no qual a razão e a sensibilidade se imbricam, formando aquilo que o filósofo anteriormente citado denominou de impulso lúdico. "Pois, para dizer tudo de vez, o homem joga somente quando é homem no pleno sentido da palavra, e somente é homem pleno quando joga". (SCHILLER, 2002, p. 80)

A consideração de que o jogo somente é possível devido à capacidade humana de imaginar, de criar e de recriar as situações da vida comum, é um aspecto fundamental para pensarmos a presença do jogo para além da sua manifestação nas práticas da cultura corporal de movimento ${ }^{3}$. Sendo assim, jogamos porque temos uma espécie de energia armazenada, em nossas faculdades imaginativas, destinadas para a ação lúdica.

A reflexão acima nos permite a compreensão de que assim como existe o Homo Sapiens (homem que sabe), o Homo Faber (Homem que produz), existe também o Homo Ludens, termo que expressa à representação da vontade humana de brincar e com isso produzir cultura. (HUIZINGA, 1980)

Outro aspecto que a nosso ver é fundamental no debate do jogo como fenômeno humano, refere-se a sua associação direta com a categoria da ludicidade. A palavra ludicidade tem origem no latim, com o termo Ludus, que significa; jogo, diversão brincadeira, euforia, prazer e alegria. Assim, não é raro ouvirmos nos espaços educativos alguém falar que tal atividade é mais ou menos lúdica, ou seja, mais ou menos alegre e divertida.
(3) Principalmente a partir da década de 1980, um conjunto de expressões oriundas das Ciências Humanas passou a habitar o debate acadêmico da Educação Física no Brasil, dando início a uma intensa disputa pelos os sentidos, as finalidades e os "rumos teóricos" do seu objeto de intervenção na escola. Nesse contexto, surgiram termos como: cultura física, cultura corporal, cultura de movimento e cultura corporal de movimento. Neste texto, optamos pela compreensão de Bracht (1999), para quem a cultura corporal de movimento se traduz em uma série de manifestações do movimentar-se humano (brincadeiras, jogos,

danças, esportes, lutas, exercícios físicos e outras práticas corporais) que tematizamos com intenções pedagógicas na escola. Nessa concepção, as práticas corporais não são concebidas como um conjunto de códigos já produzidos e prontos para serem transmitidos para os alunos, mas sim, como textos inacabados e sujeitos a diferentes formas de apropriação e reconstrução no plano da prática pedagógica. 
Huizinga (1980) quando discute a categoria da ludicidade, realiza um debate em associação com o conceito de liberdade. Assim, uma atividade é mais ou menos lúdica de acordo com o grau de liberdade momentânea na qual os sujeitos estão inseridos. Ou melhor, não existe atividade lúdica que seja também obrigatória e entediante, pois, a ludicidade emerge justamente quando a liberdade de criação se torna a característica principal da atividade realizada.

Outro ponto, é que o lúdico raramente é uma experiência que todos vivenciam do mesmo modo e com a mesma intensidade. Afinal, as sensações de liberdade, do prazer, da alegria e do divertimento variam entre os sujeitos, o que em última instância nos permite dizer que a busca pela ludicidade é algo subjetivo, que se pode encontrar não apenas no jogo ou nas práticas corporais, mas também no ato de estudar, de cantar, de conversar com amigos, de cozinhar etc. Portanto, a associação direta da ludicidade como sinônimo de jogo é equivocada quando se compreende que o espírito lúdico é algo que pode estar presente em diversas situações da vida, inclusive no trabalho!

Com as passagens acima, apontamos os argumentos que sustentam a ideia de que o jogo é uma atividade que transcende o universo das práticas corporais, pois, manifesta-se como uma dimensão fundamental da ação humana. No entanto, é evidente que conhecemos vários jogos que se apresentam como práticas corporais, ou seja, que se caracterizam pelo movimento corporal, possuindo uma determinada lógica interna e que se explicam por aspectos da cultura de cada local. Como exemplo, podemos citar a bandeirinha, a queimada, o pira-se-esconde, o cinco cortes, etc. Desse modo, é possível afirmar que o ser humano em vários momentos busca a sua liberdade em ações que tradicionalmente conhecemos como jogos ou brincadeiras populares.

\section{O olhar da Sociologia/Antropologia e da área da Educação Física sobre o jogo}

Em uma das mais clássicas obras já escritas sobre a presença do lúdico na história da vida humana, Huizinga (1980) afirma que o jogo é uma atividade exercida dentro de determinados limites de tempo e espaço, seguindo regras livremente consentidas, porém absolutamente obrigatórias, dotado de um fim em si mesmo, acompanhado de um clima de tensão e alegria, e de uma consciência de 
ser diferente da vida cotidiana, que pode ser intitulada como "não séria" e exterior à vida habitual, sendo ao mesmo tempo capaz de absorver o jogador de maneira intensa e total. Caillois (2017, p. 3739) concorda quanto à intensidade e relevância do jogo em si, bem como a respeito da seriedade das regras aplicadas nessa atividade:

Com efeito, o jogo é essencialmente uma ocupação separada, cuidadosamente isolada do resto da existência, e geralmente realizada dentro de limites precisos de tempo e de lugar. [...] O jogo não tem outro sentido que ele mesmo. É por isso, aliás, que suas regras são imperiosas e absolutas e vão além de qualquer discussão.

Nessa perspectiva, Caillois (2017) sintetiza seu entendimento sobre o jogo em algumas caraterísticas essenciais, sendo elas; atividade livre, improdutiva, separada da vida comum, com certo grau de incerteza, que acontece sempre com a presença de regras e em uma dinâmica "fictícia". Desse modo, tais características revelam que o jogo é uma atividade que absorve o sujeito da dinâmica rígida da vida cotidiana, pois, o jogo cumpre a tarefa de possibilitar que os sujeitos criem as suas próprias realidades.

Na literatura especializada da área da Educação Física, o sentido do jogo como uma atividade livre e dotada de regras flexíveis se mantém, porém, a reflexão caminha diretamente para a consideração do jogo como uma prática corporal que deve junto com as lutas, o esporte, a ginástica e a dança fazer parte do currículo da Educação Física na Educação Básica. Assim, segundo Soares e demais autores (2012), o jogo é uma invenção humana, em que a sua intencionalidade e curiosidade realizam um processo criativo que modifica imaginariamente a realidade e o presente.

Freire (2002) aponta que o jogo é o oposto do trabalho, justamente devido o trabalho ser uma atividade de privação e de cerceamento da liberdade, e o jogo ser por sua natureza livre. No jogo existe satisfação, alegria, diversão e fuga da realidade. Outro ponto, é que existe entre os humanos uma espécie de energia vital para além daquela que fazem uso em suas atividades básicas, sendo justamente essa energia que é utilizada durante a ação lúdica. Em Freire (1994) o jogo e a cultura lúdica são citados como o conteúdo mais relevante na infância, pois, podem também ser usados como instrumentos para o desenvolvimento das capacidades afetivas, motoras e cognitivas das crianças. 
Compreendemos que a relação entre jogo e cultura é um elemento fundamental para uma caracterização efetiva das ações lúdicas nos diversos contextos culturais. Pois, diferentemente do esporte, que pode ser compreendido como um fenômeno dotado de universalidades e de formas rígidas em suas estruturas internas e externas ${ }^{4}$ o jogo somente pode ser entendido por via da análise do espaço/tempo no qual se manifesta.

Desse modo, antes de falarmos se uma determinada atividade é ou não jogo, devemos compreender o sentido que os praticantes atribuem para suas ações. Como bem disse Kishimoto (2011, p. 28), "O jogo inclui sempre uma intenção lúdica do jogador". Ou seja, somente quem joga sabe que está jogando. Com isso, definir o que é jogo perpassa pela consideração do que cada cultura delimita ou não como ação lúdica, pois, "Jogo é tudo aquilo que minha percepção me disser que é jogo". (FREIRE, 2002, p. 115)

Agamben (2007) discute do ponto de vista histórico as mudanças ocorridas em certos jogos. De acordo com o pensador Italiano, muitos jogos que se conhecem atualmente têm suas origens em adorações religiosas (teor sagrado). Cabe destacar, que brincar em roda era um rito matrimonial, jogar com bola reproduz a luta dos deuses pelo sol, e assim por diante. Todavia, o mundo contemporâneo secularizou uma série de condutas lúdicas. Com isso, a dimensão do sagrado deu lugar a outros interesses, como, por exemplo, as demandas da indústria cultural, que busca sempre vender os seus jogos digitais e os seus grandes espetáculos televisivos.

Dando continuidade à reflexão sobre jogo e cultura, é instigante quando se verifica que para certas culturas indígenas o arco e flecha é uma necessidade de sobrevivência, assim como a canoagem. Porém, a indústria cultural foi capaz de transformar tais atividades vitais para os indígenas em conduta lúdica para outras culturas. Com isso, avançamos para outra reflexão, o que nos permite dizer que o jogo é sempre um fenômeno da linguagem. Assim, o significado do termo jogo no Brasil é diferente do juego no espanhol, que difere dos termos game, play, to play, player e to gamble no inglês, do ludus no Latim, do spiel no alemão, da galhofa em Portugal, e assim por diante.

Outro pensador que compreende o jogo por via da dimensão da cultura, dando ênfase no elemento da linguagem, é Wittgenstein (1991). Nessa perspectiva, o autor afirmar que jogo é um termo que pode se tornar impreciso para categorizar uma série de condutas 
e ações humanas. Assim, mais importante do que tentarmos conceituar o jogo por intermédio de caracterizações abstratas, para o filósofo austríaco devemos considerar que os jogos formam uma família, pois:

Considere, por exemplo, os processos que chamamos de 'jogos'. Refiro-me a jogos de tabuleiro, de cartas, de bola, torneios esportivos etc. O que é comum a todos eles? Não diga: "Algo deve ser comum a eles, senão não se chamariam jogos", - mas, veja se algo é comum a eles todos. - Pois, se você os contempla, não verá na verdade algo comum a todos, mas semelhanças, parentescos, e até toda uma série deles. Como disse: não pense, mas veja! (WITTGENSTEIN, 1991, p. 38)

Além das relações conceituais entre jogo e cultura discutidas acima, outras duas ideias são importantes nesse debate. A primeira é a de Huzinga (1980), de que o jogo é um fenômeno anterior à cultura, sendo assim, é na experiência lúdica que a cultura humana tem sido construída ao longo da história. Nessa mesma linha, Freire $(1994,2002)$ afirma que o jogo é por excelência um espaço de produção da cultura lúdica.

Brougére (1998) questiona a ideia acima. Pois, para o sociólogo francês, ainda que o jogo seja um espaço de produção da cultura lúdica, em primeira instância o jogador necessita aprender uma gama de signos e de condutas presentes em cada atividade lúdica. Portanto, antes de produzir cultura, o jogador deve aprender a cultura lúdica já existente, se apropriar das diversas habilidades e das formas de agir necessárias em cada brincadeira, e com isso, ser capaz de produzir novas formas de brincar.

Conforme sugere Brougére (1998, p. 5) "A cultura lúdica é, antes de tudo, um conjunto de procedimentos que permitem tornar o jogo possível". A nosso ver, a ideia de Brougére dialoga com a perspectiva educacional que defendemos para a área da Educação Física. Pois, se o jogo é um conteúdo, ele necessita ensinar algo sobre si próprio para as crianças. Sendo assim, nessa mesma linha de reflexão, a seguir discutiremos as nossas experiências com o ensino do jogo no $3^{\circ}$ ano do Ensino Fundamental. 


\section{O significado do jogo para crianças do Ensino Fundamental I}

Como modo de organizar a discussão da produção de significados a respeito do conteúdo jogo por parte dos alunos do $3^{\circ}$ ano do Ensino Fundamental, primeiramente apresentamos o Quadro 1 com a organização didática das aulas. Cabe informar, que como objetivo central dessa unidade de ensino pretendeu-se: apresentar aos alunos alguns elementos do jogo, suas características, conceito e formas (tipos de jogos). Dessa maneira, nossa avaliação ocorreu por intermédio da representação escrita, corporal e oral dos alunos sobre os conteúdos tratados.

Quadro 1 - Organização didática das aulas com o conteúdo jogo

\begin{tabular}{|c|l|l|}
\hline Aula & \multicolumn{1}{|c|}{ Conteúdo da aula } & \multicolumn{1}{|c|}{ Atividades/Procedimentos } \\
\hline 1 & $\begin{array}{l}\text { Jogos populares/tradicio- } \\
\text { nais }\end{array}$ & $\begin{array}{l}\text { Vivência/experiência com as piras (pira } \\
\text { pega, pira alta, pira cola e etc.) e do jogo } \\
\text { do tubarão e peixinho. }\end{array}$ \\
\hline 2 & nais em roda & $\begin{array}{l}\text { Vivência/experiência do curupira, do } \\
\text { dentro e fora, do vivo e morto e do pula } \\
\text { corda em roda. Construção coletiva do } \\
\text { conceito e da identificação das caracte- } \\
\text { rísticas principais do jogo. }\end{array}$ \\
\hline 3 & Jogos populares/tradicio- & $\begin{array}{l}\text { Desenho dos jogos praticados a partir } \\
\text { da representação atribuída pelos alunos } \\
\text { sobre o jogo. Construção do caderno } \\
\text { de jogos, e experiência com os jogos } \\
\text { realizados nas outras aulas com novas } \\
\text { regras. }\end{array}$ \\
\hline 4 & $\begin{array}{l}\text { Jogos Populares/tradicio- } \\
\text { nais }\end{array}$ & $\begin{array}{l}\text { Finalização do caderno de jogos. Pintu- } \\
\text { ra, construção da capa, assinatura das } \\
\text { crianças e escrita do conceito de jogo } \\
\text { produzido pelos alunos. }\end{array}$ \\
\hline 5 & $\begin{array}{l}\text { Vivência/experiência de vários jogos de } \\
\text { dramatização. Pira pega com estátua, } \\
\text { pira pega com foto, mímica, telefone } \\
\text { sem fio corporal e jogo das profissões. } \\
\text { Roda de conversa com teor avaliativo } \\
\text { sobre o nosso bimestre e contribuições } \\
\text { dos alunos para futuras experiências. }\end{array}$ \\
\hline
\end{tabular}

Fonte: elaboração dos autores

Para buscar o significado que os alunos atribuem ao jogo, utilizamos a produção do caderno de jogos como recurso principal. Nesse material didático a turma expressou tanto na forma de desenho, como na linguagem escrita, o que compreenderam 
sobre o jogo a partir dos conteúdos socializados. Com o desenho, nosso objetivo foi de identificar a representação dos alunos sobre os jogos trabalhados. Assim, conseguimos inferir qual o significado que o jogo possui para os estudantes e como o que eles escrevem e pensam sobre determinado fenômeno se encontra diretamente relacionado com o lugar e com o contexto de vida que vivenciam.

$\mathrm{Na}$ aula inicial com o conteúdo, dialogamos sobre a proposta de ensino do jogo, partindo das experiências e da compreensão dos alunos sobre esse conteúdo. Como discurso principal, apareciam os jogos e as brincadeiras tradicionais. Com base nessa constatação, seguimos nossa aula com a vivência ${ }^{5}$ desse conteúdo e com a definição do que seriam jogos populares. No final da aula, vivenciamos um jogo novo, denominado de tubarão e peixinho ${ }^{6}$. Como forma de compreensão dos jogos populares/tradicionais, seguimos a formulação de Kishimoto (2011), para quem as brincadeiras tradicionais infantis dialogam com o folclore e a cultura popular, sendo expressas em geral pela oralidade.

Nossa aula seguinte foi dividida em dois momentos. No primeiro realizamos a prática de jogos populares vivenciados em roda. Na outra metade da aula conseguimos iniciar o processo de produção de compreensão e de significados sobre o conteúdo estudado. Na sala de aula, elaboramos um conceito inicial sobre o jogo por via da identificação coletiva das principais características presentes nos jogos praticados até então. Nesse momento, as falas mais recorrentes sobre o conteúdo é que o jogo tem: brincadeira, alegria, diversão, professor, criança, corda, pessoas, poucas regras e podemos mudar regras. (ALUNOS DA E.E.E.M.F JOELSON DOS SANTOS RODRIGUES, 2018)

Analisando os termos escritos pelas crianças no caderno de jogos, percebemos que a ideia de ludicidade vinculada ao jogo se encontra presente e delineia o sentido das atividades realizadas. Em pesquisa de campo realizada na Educação Infantil, Furtado e demais autores (2019) apontam que para crianças de quatro e cinco anos, o jogo é interpretado praticamente como brincadeira e ação, ou seja, como uma prática desprovida de um corpo complexo de regras. Contudo, no grupo estudantil do Ensino Fundamental, ocorreu um processo de estudo e reflexão coletiva sobre as características do jogo, fato esse que indica a possibilidade de uma continuidade nas práticas de escolarização com esse conteúdo em diferentes níveis de ensino.
(5) Nesse momento, o termo vivência será utilizado como sinônimo de experiência no sentido de Benjamin (1985)

(6) Nesse jogo, basicamente o tubarão deve impedir que os peixinhos passem por ele e cheguem a um determinado local acordado previamente. 
(7) Caillois (2017) afirma que as atividades conhecidas como jogos de azar acabam por superar essa noção do jogo como uma ação desprovida de sentido material e lucro. Afinal, nesses tipos de jogos é justamente a tensão entre o ganhar ou perder determinado recurso financeiro que atribui sentido para a atividade.
Nesse sentido, conforme Freire (2016), podemos dizer que para além de uma prática de imposição de saberes, a educação é uma atividade que visa produzir compreensão e significados sobre os objetos estudados. Diferentemente da lógica tradicional de ensino, em uma perspectiva antropológica e dialógica, os conteúdos podem ser sempre ressignificados e reconstruídos no espaço/tempo no qual a prática educativa acontece.

Por essa perspectiva, uma prática educativa que reconhece, no sentido de Arroyo (2014), que para cada tipo de sujeitos, necessitamos de uma pedagogia singular, precisa conceber o jogo como um fenômeno que é sempre local e global ao mesmo tempo. Conforme afirma Huizinga (1980), o jogo é uma atividade habitualmente não séria, mas que também apresenta aspectos de seriedade. No jogo, os jogadores "fogem" da lógica racional da vida por um determinado tempo, por via de uma atividade sem fins materiais ${ }^{7}$, inserida dentro de um espaço e de uma temporalidade. Assim, no jogo os sujeitos constroem suas regras, que podem ser constantemente modificadas para a melhor fruição da situação lúdica.

Outro aspecto interessante presente no discurso das crianças e que dialoga com os apontamentos de Brougére (1998), refere-se à constatação de que as crianças do Ensino Fundamental identificaram as estruturas do jogo. Ou seja, a constatação do jogo como uma prática que possui regras, demostra que antes de tudo necessitamos aprender essas regras para jogar, o que também não exclui a possibilidade de recriação dessas como bem disseram as crianças.

Em nossos registros de acontecimentos significativos da aula, anotamos as dificuldades que alguns alunos tiveram com as regras e com a compreensão da dinâmica de certos jogos. Com base nessas anotações, nossa prática pedagógica se orientava não apenas para um fazer pelo fazer dos jogos e das brincadeiras propostos, mas sim, para uma real apropriação por parte das crianças dos elementos que compõem cada atividade lúdica. Com isso, é possível afirmar que quanto mais a criança domina diferentes aspectos da cultura lúdica, maior é a sua possibilidade de usufruir de um brincar cada vez mais criativo e autônomo.

$\mathrm{Na}$ terceira aula, avançamos no processo de produção de significados e de compreensão sobre o jogo com a tarefa coletiva de construção do caderno de jogos. Nessa aula, os alunos realizaram um desenho sobre os jogos vivenciados até o momento. Em seguida, praticaram novamente os jogos até então conhecidos, porém, 
com a tarefa de modificarem coletivamente as regras e as formas de jogar, para assim, os alunos observarem a dimensão criativa e imaginativa do ato de reconstruir uma determinada prática.

Primeiramente, sobre os desenhos realizados, percebemos que as crianças sempre tentavam expressar o momento de maior ação e tensão presente em cada jogo. Chama a atenção o processo de representação das crianças, pois, algumas delas desenharam o jogo do tubarão e peixinho não com as crianças, mas sim, com o próprio tubarão e os peixinhos simulando a dinâmica da brincadeira. No processo de reconstrução das regras do jogo, é possível notar que após a real aprendizagem de elementos constitutivos desse fenômeno, em especial da presença impreterível de regras, as crianças foram capazes de criar diversas outras formas de experiências lúdicas. Tal fato sugere que as crianças compreenderam a dimensão flexível das regras no jogo.

Retornando a perspectiva de Schiller (2002) e de Kant (2010), podemos dizer que as crianças exercitaram aquilo que torna possível a existência do jogo, ou seja, a capacidade humana de imaginação e de reconstrução da realidade. Se fossem "dominadas" pela lógica da racionalidade técnica presente nos grandes centros urbanos, ainda assim não poderíamos dizer que as crianças do Ensino Fundamental não conseguiram criar situações lúdicas, pois, imaginar e buscar o lúdico são impulsos/pulsões próprios dos seres humanos.

Ainda na terceira aula, o conceito de jogo ganhou novos significados, assim como a manifestação do lugar em que se joga. Desse modo, quando perguntados sobre onde podemos praticar os jogos, tivemos resposta do tipo: na igreja, na rua, em casa, na cidade, na praia, na arena, no campo, na praça, na areia, na piscina, no rio e na escola. (ALUNOS DA E.E.E.M.F JOELSON DOS SANTOS RODRIGUES, 2018) Ou seja, o jogo é uma atividade que embora possa ser considerada uma prática da cultura universal da humanidade, recebe significados sempre de acordo com o espaço/ tempo no qual se manifesta. Tal apreensão das crianças corrobora com os apontamentos de Huizinga (1980) de que o jogo é uma atividade exercida sempre em uma esfera de tempo e de espaço determinados.

Diferentemente do que acreditam algumas teorias pedagógicas tradicionais e críticas, os conteúdos escolares se modificam em decorrência da percepção que os sujeitos possuem sobre eles. Pois, se mudam os sujeitos mudam as pedagogias, bem como, a 
compreensão sobre os temas de estudo. No caso da cultura corporal de movimento, um real processo de ensino-aprendizagem dessas manifestações não pode desconsiderar o contexto concreto no qual os educandos se encontram, assim como, não pode desprezar o que significa um jogo, uma luta, uma dança ou um determinado esporte para cada criança, jovem e adulto.

Na lógica argumentativa de Santos (2018), todo conhecimento é ao mesmo tempo local e global. Melhor dizendo, todo conhecimento é sempre produzido em um lugar específico, fazendo parte tanto do contexto local no qual se situa, como também da cultura universal da humanidade. No caso específico do jogo, Neira (2008) afirma que se trata de uma prática corporal valorosa que pode servir no trabalho com a cultura popular, visando à formação da identidade e a escolarização dos estudantes.

Na aula seguinte, avançamos na finalização do caderno de jogos com o término dos desenhos, construção da capa e finalização dos conceitos por parte dos alunos. Nesse momento, também aproveitamos para discutir novamente o conteúdo em questão, buscando fazer com que os alunos refletissem sobre o jogo agora para além da compreensão imediata e sincrética que possuíam a respeito no começo do bimestre.

Após esse ciclo de trabalho com os jogos populares, na última aula prevista para este conteúdo trabalhamos com os jogos de dramatização. Como um dos objetivos da unidade era a apresentação de diferentes tipos de jogos, no último encontro tematizamos os jogos de dramatização, que de acordo com Bregolato (2007), são atividades em que a imaginação e o potencial de encenação ganham destaque, pois, as crianças elaboram experiências ilusórias a partir de aspectos reais do mundo cotidiano.

Nesses jogos, tivemos a experiência direta com aquilo que Benjamin (1985) denomina de faculdade mimética dos homens, e que Caillois (2017) classifica como mimicry. Assim, o imitar, o recriar, o encenar e o dramatizar foram as condutas mais exploradas nessa aula, corroborando com a afirmação de Soares e demais autores (2012) de que no jogo se cria sempre uma situação imaginária.

Cabe destacar, que apesar das significações das crianças terem sido registradas no caderno de jogos principalmente a partir das suas representações tidas como positivas, isso não quer dizer que a dimensão da ludicidade/liberdade esteve presente em todos os jogos realizados e da mesma maneira em todas as crianças. 
Portanto, consideramos que as experiências com o lúdico foram diversificadas, no entanto, as crianças expressaram significados e modos de compreensão similar do conteúdo estudado.

\section{Considerações finais}

Por via da apresentação da organização didática do conteúdo jogo com alunos do $3^{\text {a }}$ ano do Ensino Fundamental e da avaliação por intermédio da construção do caderno de jogos, conseguimos compreender qual o significado que o jogo possui para educandos da cidade de Ponta de Pedras/PA, que estudam em uma escola na região do interior do município. Assim, o jogo para os estudantes é uma atividade lúdica (livre) realizada a partir de regras coletivamente acordadas, podendo ser praticado em diversos espaços, como, por exemplo, na escola, na rua, na praia e na praça, refletindo o lugar de onde os sujeitos falam, suas condições de vida e as culturas lúdicas presentes na região.

Como o objetivo central deste estudo sugere, nossa ênfase esteve na identificação por via do caderno de jogos, das anotações sobre as aulas e da observação, dos significados produzidos pelas crianças durante o processo educativo desenvolvido. Como principais resultados, destacamos que o grupo estudantil em questão compreende o jogo, principalmente, a partir dos seguintes termos: brincadeira, alegria, diversão, professor, criança, corda, pessoas, poucas regras e podemos mudar regras.

Com essa pesquisa, esperamos contribuir para o acúmulo de possibilidades didático-pedagógicas com o conteúdo jogo nas aulas de Educação Física. Além disso, este trabalho buscou evidenciar que embora o jogo seja tradicionalmente considerado um conteúdo da Educação Física, a sua compreensão como fenômeno transcende o universo das práticas corporais, o que fatalmente sugere que na escola os alunos podem ter acesso a práticas de escolarização com o jogo ainda mais aprofundadas e orientadas pela perspectiva da interdisciplinaridade. Nesse sentido, indicamos que futuros estudos podem investigar as possibilidades de organização curricular e o trato com o conteúdo jogo também na Educação Infantil, nos últimos anos do Ensino Fundamental, no Ensino Médio e na formação inicial de professores de Educação Física.

Por fim, reforçamos a ideia de que os conhecimentos da cultura corporal de movimento ganham sentido quando localizados 
no tempo/espaço em que se manifestam. Logo, um trabalho com a generalização desses saberes corre o risco de desprezar todo o imaginário e as representações que diversos sujeitos e culturas possuem a respeito das práticas corporais. Portanto, se todo conhecimento é local e global ao mesmo tempo, os conhecimentos da cultura corporal de movimento também adentram nessa dinâmica. Afinal, nenhuma forma de educação pode desprezar o fato de que são sempre os sujeitos os reais produtores do significado que as práticas culturais possuem para as suas vidas.

\title{
The game in Physical education classes: meanings attributed by the children
}

\begin{abstract}
It is a theoretical reflection derived from a pedagogical experience from the work with the content played in physical education classes in the initial grades of elementary school. Thus, in this study we aim to: analyze the way students from the municipality of Ponta de Pedras/PA of the initial grades of elementary school produce meanings about the content played in physical education classes. Regarding methodological procedures, the study is found in the field of action research, using observation and records in the form of images, videos and didactic materials for data collection. For analysis, it uses a bibliographic framework alluding to the philosophy and anthropology of the game. We conclude that the game has numerous meanings for the children in question, expressed in the terms: play, joy, fun, teacher, child, rope, people, few rules and we can change rules. Such terms, as found in the specialized literature, seized as fundamental characteristics of the game phenomenon.
\end{abstract}

Keywords: School physical Education. Game. Meaning Production.

\section{El juego en las clases de educación física: significados atribuidos por los niños}

\begin{abstract}
Resumen: Es una reflexión teórica derivada de una experiencia pedagógica del trabajo con el contenido desempeñado en las clases de educación física en los grados iniciales de la escuela primaria. Así, en este estudio pretendemos: analizar la forma en que los estudiantes del municipio de Ponta de Pedras/ PA de las notas iniciales de la escuela primaria producen significados sobre el contenido que se juega en las clases de educación física. En cuanto a los procedimientos metodológicos, el estudio se encuentra en el campo de la investigación de acción, utilizando la observación y los registros en forma de imágenes, vídeos y materiales didácticos para la recopilación de datos. Para el análisis, utiliza un marco bibliográfico alusión a la filosofía y antropología del juego. Concluimos que el juego tiene numerosos significados para los niños en cuestión, expresados en los términos: jugar, alegría, diversión, maestro, niño, cuerda, gente, pocas reglas y podemos cambiar las reglas. Tales términos, como se encuentra en la literatura especializada, se presentan como características fundamentales del fenómeno del juego.
\end{abstract}

Palabras-clave: Educación física escolar. Juego. Producción de significado. 


\section{Referências}

AGAMBEN, Glorgio. Profanações. São Paulo: Boitempo Editorial, 2007.

ARROYO, Miguel. Outros sujeitos, outras pedagogias. 2. ed. Petrópolis, RJ: Vozes, 2014.

ALUNOS DA E.E.E.M.F JOELSON DOS SANTOS RODRIGUES. Caderno de jogos do $3^{\circ}$ ano do Ensino Fundamental. Ponta de Pedras, 2018.

BENJAMIN, Walter. Magia e técnica, arte e política: ensaio sobre literatura e história da cultura. São Paulo: Brasiliense, 1985. (Obras Escolhidas, 1).

BRACHT, Valter. Educação fisica e ciência: cenas de um casamento (in) feliz. Ijuí: Ed. UNIJUÍ, 1999.

BRACHT, Valter. Sociologia crítica do esporte: uma introdução. 3. ed. Ijuí: Unijui, 2005.

BREGOLATO, Roseli Aparecida. Cultura corporal do jogo. 2. ed. São Paulo: Ícone, 2007.

BROUGÉRE, Gilles. A criança e a cultura lúdica. Revista da Faculdade de Educação, São Paulo v. 24, n. 2 July/Dec. 1998.

CAILLOIS, Roger. Os jogos e os homens: a máscara e a vertigem.

Petrópolis, RJ: Vozes, 2017.

FREIRE, João Batista. O jogo: entre o riso e o choro. Campinas, SP: Autores Associados, 2012.

FREIRE, João Batista. Educação de corpo inteiro: teoria e prática da educação física. 4. ed. São Paulo: Editora Scipione, 1994.

FREIRE, Paulo. Professora sim, tia não: cartas a quem ousa ensinar. 26. ed. São Paulo: Paz e Terra, 2016.

FURTADO, Renan et al. O jogo nas aulas de educação física na educação infantil: do interesse pedagógico da educação física à produção de compreensão das crianças. Revista Kinesis, Santa Maria, v. 37, p. 1-12, 2019 .

FURTADO, Renan; BARRETO, Libório; RAMOS, Adso. Pedagogia críticosuperadora e o modelo pendular: uma aproximação necessária para o ensino dos esportes coletivos na escola. Cadernos UniFOA, Volta Redonda, n. 40, p. 83-94, ago. 2019.

FURTADO, Renan; BORGES, Carlos Nazareno. A condição esportiva. Educação, Santa Maria, v. 44, 2019.

GUTTMANN, Allen. From ritual to record: the nature of modern sports. New York, Columbia University Press, 1978.

HUIZINGA, Johan. Homo ludens: o jogo como elemento da cultura. 2. ed. São Paulo: Perspectiva, 1980. 
KANT, Immanuel. Crítica da faculdade do juízo. Rio de Janeiro: Editora Forense, 2010.

KISHIMOTO, Tizuko. O jogo e a educação infantil. In: KISHIMOTO, Tizuko (org.). Jogo, brinquedo, brincadeira e a educação. 14. ed. São Paulo: Cortes, 2011.

LESSA, Juliana. O conceito de experiência em Walter Benjamin: elementos para pensar a educação na infância. Revista Zero-a-Seis, Florianópolis, v. 18, n. 33 p. 108-121,| jan./jun. 2016.

NEIRA, Marcos Garcia. A cultura corporal popular como conteúdo do currículo multicultural da educação física. Pensar a Prática, v. 11, n. 1: p. 81-89, jan./jul. 2008.

PREFEITURA MUNICIAPL DE PONTA DE PEDRAS. Disponível em: https://www.pontadepedras.pa.gov.br/omunicipio.php. Acesso em: 02 jun. 2019.

SANTOS, Boaventura. Um discurso sobre as ciências. 8. ed. São Paulo: Cortez, 2018.

SCHILLER, Friedrich. A educação estética do homem. 4. ed. São Paulo: Editora Iluminuras, 2002.

SEVERINO, Antônio. Metodologia do trabalho científico. 24. ed. São Paulo: Cortez Editora, 2016.

SOARES, Carmen et al. Metodologia do ensino de educação física. 2. ed. São Paulo: Cortez, 2012.

THOMAS, Raymond. Histoire du sport. Paris, Universitaires de France, 1991.

WITTGENSTEIN, Ludwig. Investigações filosóficas. São Paulo: Nova Cultural, 1991.

Submetido em 07/11/2019. Aceito em 01/06/2020. 